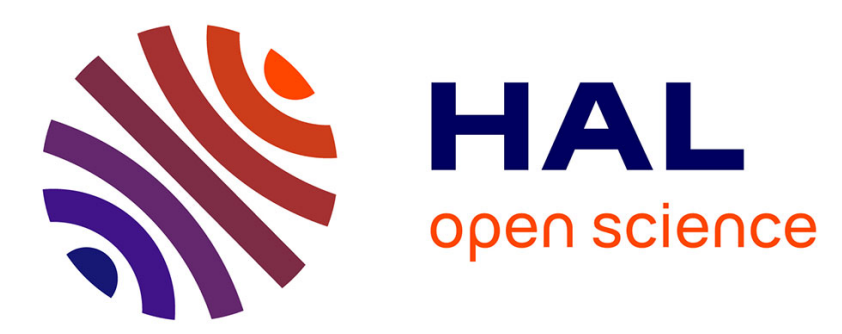

\title{
A longitudinal perspective on car ownership and use in relation with income inequalities in the Paris metropolitan area
}

\author{
Benoît Cornut, Jean Loup Madre
}

\section{To cite this version:}

Benoît Cornut, Jean Loup Madre. A longitudinal perspective on car ownership and use in relation with income inequalities in the Paris metropolitan area. Transport Reviews, 2017, 37 (2), pp.227-244. 10.1080/01441647.2016.1245218 . hal-01467237

\section{HAL Id: hal-01467237 https://hal.science/hal-01467237}

Submitted on 14 Feb 2017

HAL is a multi-disciplinary open access archive for the deposit and dissemination of scientific research documents, whether they are published or not. The documents may come from teaching and research institutions in France or abroad, or from public or private research centers.
L'archive ouverte pluridisciplinaire HAL, est destinée au dépôt et à la diffusion de documents scientifiques de niveau recherche, publiés ou non, émanant des établissements d'enseignement et de recherche français ou étrangers, des laboratoires publics ou privés. 


\title{
A Longitudinal Perspective on Car Ownership and Use in Relation with Income Inequalities in the Paris Metropolitan Area
}

\author{
BENOÎT CORNUT"§ and JEAN-LOUP MADRE*
}

* UPE (University of Paris-Est) and IFSTTAR-AME-DEST, 14-20 Boulevard Newton, Cité Descartes, Champs-sur-Marne, Marne-la-Vallée Cedex 2, F-77447, France

\begin{abstract}
The objective is to analyse the evolution of car ownership and use in the Paris region according to the standard of living of households and the place of residence (Paris, inner suburbs and outer suburbs). Based on annual panel surveys from 1974 to 2013, we show that a maximum of car use has been reached in the 1990s in the Paris region but the date of appearance of car ownership and use saturation differs according to the zone of residence (earlier in the City of Paris). The Gini index and the Q4/Q1 ratio are also computed to describe the evolution of inequalities in the population. In the Paris region, car ownership and use inequalities have strongly reduced since the 1970s. However, the levels of inequalities are higher in dense areas than in the outer suburbs where the necessity to own a car tends to homogenise travel behaviour. Last, if the Gini index is low because global inequalities are weak, inequalities remain important for low income groups, especially in the outer suburbs where the indicators have to be interpreted as indicators of inequity.
\end{abstract}

Keywords: car ownership; annual mileage; inequalities; economic indicators; Paris region 


\section{Introduction}

After a rise during several decades, a significant inflection of car travel behaviour has been observed since the beginning of the 2000s. Indeed, car use per head and in some cases total car traffic, have slowed and seems to reach a saturation threshold in several industrialized countries (ITF 2011; Millard-Ball \& Schipper, 2011). In France, the evolution is similar where a stagnation of car traffic has been observed since 2003 in National Accounts (CCTN, 2012).

This levelling off is observed in particular in largest urban areas like Lyon, Lille, Rouen, Reims, Rennes and Rouen (Hivert et al., 2008). In the Paris region (STIF 2012), trips have become less car-oriented (1.46 trips by car person per day in 2010 versus 1.54 in 2001) while mobility by public transport has increased ( 0.78 trips per person per day in 2010 versus 0.68 in 2001).

In parallel to the downturn of car traffic per individual, we also note a slowing down of car ownership growth and even a decrease in the central part of London and Paris (STIF, 2012) where new forms of trips are developing: revival of bicycle with self-service bike, twowheeled motorized vehicles and new automobile services (Autolib'...).

The Paris region (Ile-de-France) is an interesting area from the point of view of both social and spatial equity. Even if the difference with the other regions in France has considerably weakened, the average income per capita is still $15 \%$ higher than the national average in the 2000s (while it was more than 30\% higher in the 1970s). It is also the most heterogeneous region in France (Madre, 1989), with the highest income levels in Paris and in the Western suburbs, but also with poor populations, mainly in the Eastern and Northern part of the region. Population density is much contrasted particularly between the City of Paris and the outer suburbs. However, urban sprawl has slowed in the 2000s, with more population growth inside Paris and in the inner suburbs than in the outer suburbs, except for the Seine-et-Marne department in the East. Furthermore, public transport network is well developed (at least in the central part of the region) but it doesn't avoid a congestion of roads and public transports. The objective of the study is double. First, we tackle the question of 'Peak car' in the Paris metropolitan area from the point of view of inequalities by showing the social diffusion (Choquet, 1983) of car ownership (number of cars per adult) and use (kilometres travelled per households) from the highest to the lowest income group. The aim is to qualify the change in car ownership and use trends by taking into account the spatial differentiation of the population according to the zone of residence (City of Paris, inner suburbs, outer suburbs) combined with a distinction based on socio-economic status (the standard of living of households). Our work examines the influence of territory and population heterogeneity. It enables the detection of possible opposite trends for car ownership and use, in particular different temporalities for the emergence of saturation and to question whether the change in trend could be a long term or a short term phenomenon.

Second, our approach examines the evolution of car ownership and use gaps between income groups and residential areas over time through the use of two economic indicators of inequality applied to transport: the Gini index and the Q4/Q1 ratio (see the methodological section for a description of these indicators). Furthermore, car availability and kilometres travelled can be seen as an implicit measure of households' accessibility to services and key 
activities. Thus, the indicators are used in combination as a proxy of the potential gap of accessibility related to income inequalities which can induce problems in social inclusion.

A literature review will be presented in the next section, focussing on 'Peak Car' hypothesis, transport-related social disadvantages and equity perspectives. Section 3 describes the panel data, continuously collected since the mid-70s and the methodology used. The main results are shown in sections 4 and 5. Finally, we discuss the limits and the implications of our research concerning the evolution of inequalities and the potential interpretations in terms of equity.

\section{Literature Review}

\subsection{Peak Car}

The reduced growth and often the levelling off of car use is a general phenomenon observed in many developed countries at an aggregated level. Goodwin (2012) has expressed the different scenarios for the future of car use and among all the 'Peak Car' which is a hypothesis that car use, which has levelled off or even decreased could be an early sign of a long term decline. Thus, research issues tackle the potential causes of this break in trend which could be due to a combination of multidimensional drivers (economic situation, policy, technology, cultural changes, etc.).

It is usually agreed that the slowdown of traffic growth is influenced by the economic situation and in particular by the rise in fuel price during the 2000s (SOeS, 2012). While the elasticity of car traffic to fuel price was relatively weak during the period 1970s-1990s, it has tended to strengthen in the 2000s (Litman, 2013). Indeed, the response of households is stronger during a long period of rise in fuel price (2004-2008) and of volatility (since 2008) (Collet, 2012; Hivert \& Madre, 2012). Gargett (2012) who has gathered longitudinal data for 25 countries explains this levelling off by real petrol prices and also by fluctuations in the economy and a saturating effect of time. According to Metz (2010), the saturation of demand for daily travel is due to the diminishing marginal utility of additional trips which tends to increase a reluctance to travel further.

Another driver is re-densification. There is a movement of population in large metropolitan areas favouring the density of population and contributing to a reduction of car use (Goodwin \& Van Dender, 2013; Headicar, 2013). Buehler and Pucher (2012) show the importance of land-use policies coupled with public transport supply to favour alternative modes and reduce car use. In France, De Solère (2012) explains how a strong effort made to improve public transport supply in many cities (in particular with an investment in tramways) has contributed to reduce car traffic in the 2000s.

There is also a change in travel behaviour for new generations. At the turn of the 2000s, the percentage of young people with a driver's license and having a car has decreased compared with the preceding generations in several developed countries (Sivak \& Schoettle, 2012; Kuhnimhof et al., 2012; Delbosc \& Currie, 2013). The evolution in activity programs (e.g. no trip back home at lunch time) (Hubert et al, 2013) and the possible influence of information and communications technology should play a role, but their effect remains unclear. 
While the slowdown of car travel growth is a general phenomenon, we have chosen to disaggregate the analysis in order to take account of social groups and of their place of residence. Moreover, we consider both car ownership and use. This perspective permits to question the mobility gap between different groups of population and to tackle the problem of transport disadvantages.

\subsection{Transport-Related Social Disadvantages}

The distribution of access is far from uniform and differs significantly between individuals. Accessibility is shaped by two structuring dimensions: mode availability and space (Martens et al., 2012). First, space is an important determinant since the level of accessibility depends strongly on the residential location. The distribution of accessibility is unequal among the population because people living in a city centre will have more opportunities than counterparts residing in periphery (Martens et al., 2012).

Then, the availability or unavailability of the dominant transport mode strongly influences the accessibility and people's life opportunities (Lucas, 2006). As automobile is often the dominant mode in developed countries, car availability is a prerequisite to identify the population facing problems of accessibility and potential social disadvantages.

Even if the impact may be more limited in some locations such as city centres (Kwok \& Yeh, 2004), the access to key facilities is reduced without a car. In particular, people without a car are also facing major difficulties in finding a job (Ong and Blumenberg, 1998; Cervero, 2004; Wenglenski, 2004).

A significant number of studies take an interest in social disparities in mobility. Studies in particular in the UK (SEU, 2003), in the US (Murakami \& Young, 1997; Pucher \& Renne, 2003) and in France (Mignot \& Rosales-Montano, 2006; Orfeuil, 2004; Paulo, 2007) stipulate that in a given spatial context defined (e.g. in term of density), low income households have generally less cars than richer people, and low income is correlated with shorter commuting distance and a lower frequency of trips.

Thus, a lack of access to transport and a reduced use of transport may limit people's accessibility and lead to social disadvantages and exclusion. The concepts and theories of social exclusion emerged from the mid-1990s (In the UK the Social Exclusion Unit has been created in 1997 and the French National Observatory of poverty and Social Exclusion has started in 1998). It has been later explored by transport researchers as an area of interest (Lucas, 2012). Kenyon et al. (2002) define transport-related social exclusion as 'the process by which people are prevented from participating in the economic, political and social life of the community because of reduced accessibility to opportunities, services and social networks, due in whole or part to insufficient mobility in a society and environment built around the assumption of high mobility'. Church et al. (2000) show the multidimensional nature of the problem and group factors that may limit the mobility into seven categories (physical exclusion, geographical exclusion, exclusion from facilities, economic exclusion, time-based exclusion, fear-based exclusion and space exclusion). Lucas (2012) provides a conceptual framework showing the interactions between transport disadvantage (No car, poor public transport services, high fares, no information, fear of crime) and social disadvantage 
(Low income, no job, low skills, ill-health, poor housing) contributing to problems of inaccessibility and favouring social exclusion.

\subsection{Equity Concerns}

Questioning transport-related social exclusion also entails political decisions in terms of equity and how it could be taken into account in a project evaluation. As noted by Pucher \& Renne (2003) car ownership difficulties might be interpreted as fundamental inequity in the transport system. Different approaches of equity in transport can be distinguished. First, horizontal equity (egalitarianism, pure equality) expresses that a society should treat all people equally in considering individuals as equal in ability and need. Equal individuals should receive equal shares of resources and bear equal costs; it should avoid favouring one individual or group over others (Litman, 2014). However, the perfect equality is not always desirable and often impossible to achieve. In the case of accessibility, the distribution can't be equal because of the existence of centres and peripheries (Puu, 2005; Martens et al. 2012). Thus, we find also vertical equity (Litman, 2014) which considers the distribution resources between individuals with different abilities and needs. In this case, it prioritises the needs of specific groups over others. Vertical equity relates to the Rawlsian theory of equity where the aim is to improve the situation of the worse off in priority. This concept of equity is more adapted to answer a problem of transport-related social disadvantages.

Different approaches of vertical equity can be addressed. Sufficientarianism expresses that everybody should be above a certain minimum threshold, which corresponds to a sufficient level of basic needs and guarantee a minimum level of social integration. Martens et al (2012) suggest placing a maximum gap between the population groups with the lowest and the highest accessibility while maximising average access (maximax principle). We can also consider the principle of equalisation (Martens, 2011). The aim is to prefer a project that narrow the existing gap in the society over alternatives that may consolidate or widen these gaps (see also Rietveld et al., 2007, p.33). Thus, it encourages a policy equalising the relative level of accessibility between different social groups. Contrary to sufficientarianism which use a strict threshold which is hard to conceptualise, prioritarianism proposes to sort the population in terms of their accessibility levels and to give a higher weighting of benefits for people with a lower accessibility.

\section{Methodology}

\subsection{Data}

This research is based on two annual nationwide household surveys (representative for the Paris region describing both car ownership and annual mileage:

- The Continuous Household Surveys (ECAM) conducted from 1974 to 1994 by the National Institute of Statistics (INSEE) among a sample of dwellings drawn from the census. 10000 to 13000 households responded by interview each year, of which about one third had been also interviewed one year before. 
- The Car Fleet Surveys (Parc-Auto) panel survey is a postal survey conducted by the private marketing research institute TNS-Sofres. Each annual wave includes 6,000 to 7,000 volunteer respondent households, of which about $3 / 4$ have already responded the year before. This survey is available since 1984 and is still on going. It has taken up from 1994 the abandoned questions about automobile present before in ECAM surveys.

The ECAM and Car Fleet surveys have a common set of comparable variables: Households are described in terms of annual income (at least 12 brackets), zone of residence, family composition (age, gender, etc.), with some data on cars (age, type of fuel, annual mileage...). Despite some differences in the methodology between the two surveys, we have checked that these two sources verified coherent levels and evolutions of car ownership and use during the period 1984-1994 (years in common for the two surveys).

This analysis has been carried out separately for different zones of residence: Paris, inner suburbs and outer suburbs. There is an important contrast between the City of Paris with an excellent public transport system and peripheral zones with car dependency (Dupuy, 1999). We have chosen to focus notably on fuel because it is the most volatile component of car use price and most econometric models show that it is a good explanatory factor of car use. Thus, the analysis is conducted for the period 1984-2013 considering sub-periods of 5 years, according to the evolution of fuel price:

- 1984-1988 is a sudden drop in fuel price (oil counter-shock);

- In 1989-1993 and 1994-1998, fuel price is low, and the development of diesel cars using a $40 \%$ cheaper fuel induces a decrease in the cost of driving;

- Starting with a peak in 2000, 1999-2003 is the beginning of an upward trend;

- Then a continuous rise from 2004 to mid-2008;

- And a period of volatility from mid-2008 onwards.

\subsection{Population Sorted By Standard of Living}

To obtain a homogeneous database over time, the households have been sorted by standard of living $^{2}$ for each year in each residential zone. Using standard of living rather than level of income permit to homogenise households having different family compositions (two households with the same income will not have the same purchasing power if they have children or not). Finally, in order to take into account the influence of inflation over time, current incomes have been transformed into real incomes $(2013=100)$ in using the consumer price index as deflator.

To characterise car ownership, our analysis focuses on the average number of cars per adult which is the number of cars in the household divided by the total number of adults (i.e. persons over 18, the minimum age for obtaining a driving licence in France). For car use, kilometres driven per household are computed, which corresponds to the sum of the estimated annual mileages for the cars at the disposal of the surveyed household.

\footnotetext{
2 The standard of living is defined by the annual income per consumption unit, using the middle of income brackets and the Oxford scale (the weight is 1 for the head of the household, 0.7 for the other persons over 14 years old, and 0.5 for the children under 14).
} 
Moreover, the sub-groups have been calibrated in order to have enough people in each of them. The objective is that the mean value calculated in each subgroup of the sampling tends towards the real mean of the population. We have checked for each period that at least 100 households are present, in each quarter of household distribution and in the different zones under study in order to minimise bias in the estimation (Verbeek \& Nijman, 1992).

\subsection{Indicators of Inequality}

The inequalities of income per household have decreased rapidly until the mid-80s, then have remained constant only from mid-80s to early 90s, and increase since the 1993 recession in particular through the rise of income of richest people. The ratio Q4/Q1 of income inequalities is around 3 today. To analyse car ownership and use in relation to economic inequalities, we have chosen two economic indicators applied to transport. The first one is the Q4/Q1 ratio. The households have been classified into four standard of living groups (i.e. real income per consumption unit). Q1 represents the mean value for the lowest quarter of the standard of living distribution while Q4 is the mean value of the highest quarter. Quarter 1 corresponds to $60 \%$ to $70 \%$ of the median value (the poverty threshold is often estimated at $60 \%$ of the median standard of living).

The second indicator is the Gini index. This index represents the dispersion of a variable across the population and is a most commonly used measure of inequality. This coefficient is often used to measure the income inequality in a country; however it can be applied to any quantity that can be cumulated across a population. Here, the Gini index is applied to the unequal distribution of cars and mileage over income distribution. The Gini coefficient can be approximated by the following formula (Brown, 1994):

$$
\mathrm{G}=1-\sum_{\mathrm{k}=1}^{\mathrm{n}}\left(\mathrm{X}_{\mathrm{k}}-\mathrm{X}_{\mathrm{k}-1}\right)\left(\mathrm{Y}_{\mathrm{k}}+\mathrm{Y}_{\mathrm{k}-1}\right)
$$

Where $X_{k}$ is the cumulated proportion of the population (sorted by household income per consumption units) with $X_{0}=0$ and $X_{n}=1$ and $Y_{k}$ is the cumulated proportion of the variable of interest (number of cars or annual mileage) with $Y_{0}=0$ and $Y_{n}=1$. We have sorted the population by household income per consumption units in order to compute the level of overall inequality of access to car and of car use in relation with income inequalities. Furthermore, the Gini index has already been applied to transport (Karlström \& Franklin, 2009; Delbosc \& Currie, 2011; Berri et al., 2014; Lucas et al., 2015).

In this paper, we focus on the link between social disparities (standards of living), geographical disparities (zones of residence) and mobility (car ownership and annual mileage) identifying potential vulnerable segments of the population: low income, no car, living in outer suburbs. These two indicators can be interpreted as complementary for the analysis of economic inequalities. The unweighted Gini index represents the overall inequalities in the population for the variable of interest, while the Q4/Q1 ratio compares the extreme quarters of the standard of living distribution, thus putting the stress on low and high income groups. In terms of distributive principles, the Gini index can refer to egalitarism (Lucas et al., 2015) because it expresses the gap with regards to perfect equality while the Q4/Q1 ratio can refer to vertical equity because it expresses the gap remaining between specific income groups. In the 
discussion, we propose to compare the implications of these indicators in terms of policy decision making.

\section{Car Ownership}

\subsection{A Converging Behaviour for Most Inhabitants}

The average number of cars per adult has risen from 0.3 in the early $1970 \mathrm{~s}$ to 0.5 in the $2010 \mathrm{~s}$ (figure 1). There is a positive link between the level of car ownership and the level of income since a wealthier household is more motorised than a poorer one. There has been an increase of car ownership over time in each income quarter. However, in quarter 4 the saturation is old since the number of cars per adult has remained around 0.5 for three decades. For the intermediate quarters Q2 and Q3, the growth of car ownership has been relatively constant and their levels have reached that of Q4 in the early 2010s. Contrary to the richer quarters, there is not a catching up effect for the first income quarter (Q1) for which car ownership has tended to stabilise around 0.4 cars per adult since the mid-2000s.

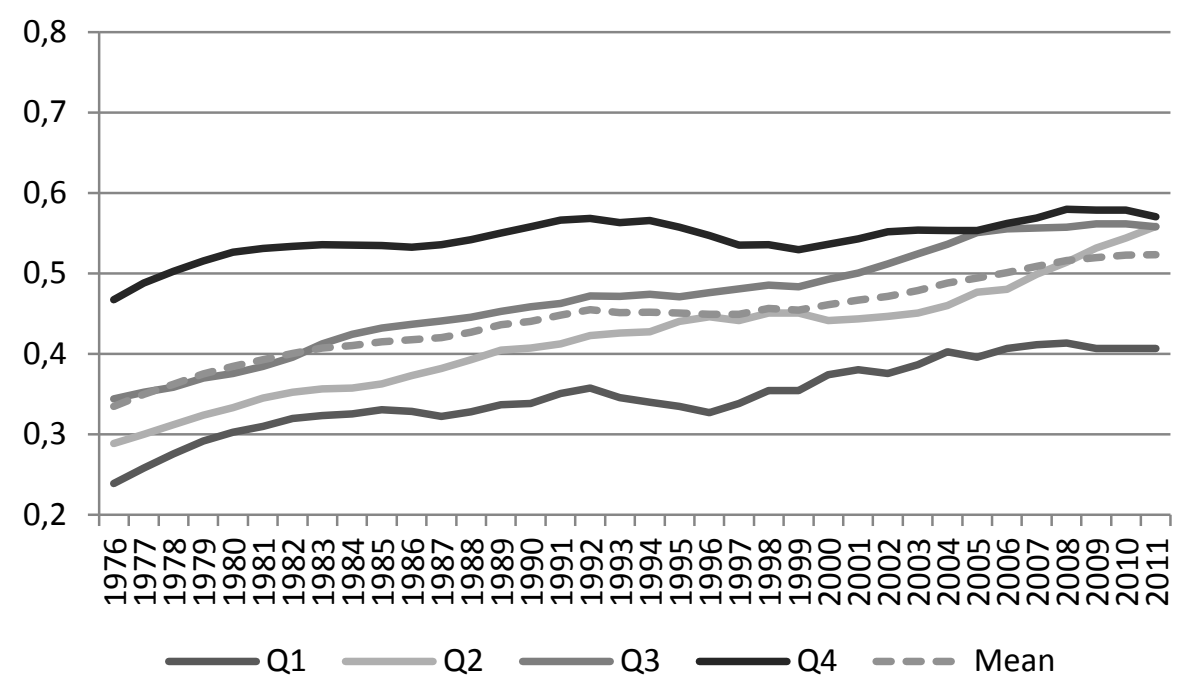

Figure 1. Average number of cars per adult by income quarter per consumption unit in the Paris region (5-year MA).

Source: Continuous Household Surveys (1974-1994) and Car fleet Surveys (1994-2013)

The democratisation of automobile has begun during the post-war economic boom (19451975). Like in most countries in the world, car ownership has developed earlier in the capital city than in the rest of France (the proportion of motorised households in the conurbation of Paris has been higher than elsewhere in France until the mid-1960s), but, mainly because of density, the level of car ownership in the Paris region is now substantially lower $(0.5$ compared to 0.7 cars per adult in France in the beginning of the 2010s). 
Progressively, the majority of the population has owned a car (except the City of Paris) because automobile is often the most suitable travel mode allowing a large set of destinations, in particular when no alternative to automobile is available. This implies a reduction of inequalities between income groups. Indeed, the Gini index for the average number of cars per adult has decreased from 0.14 in the mid-70s to 0.05 nowadays (figure 2 ). The Q4/Q1 ratio follows the same pattern since this coefficient has decreased from 1.9 to 1.4 nowadays. However, these two indicators have stagnated during the last decade showing that the process of diffusion of automobile in the population could have reached its limits.

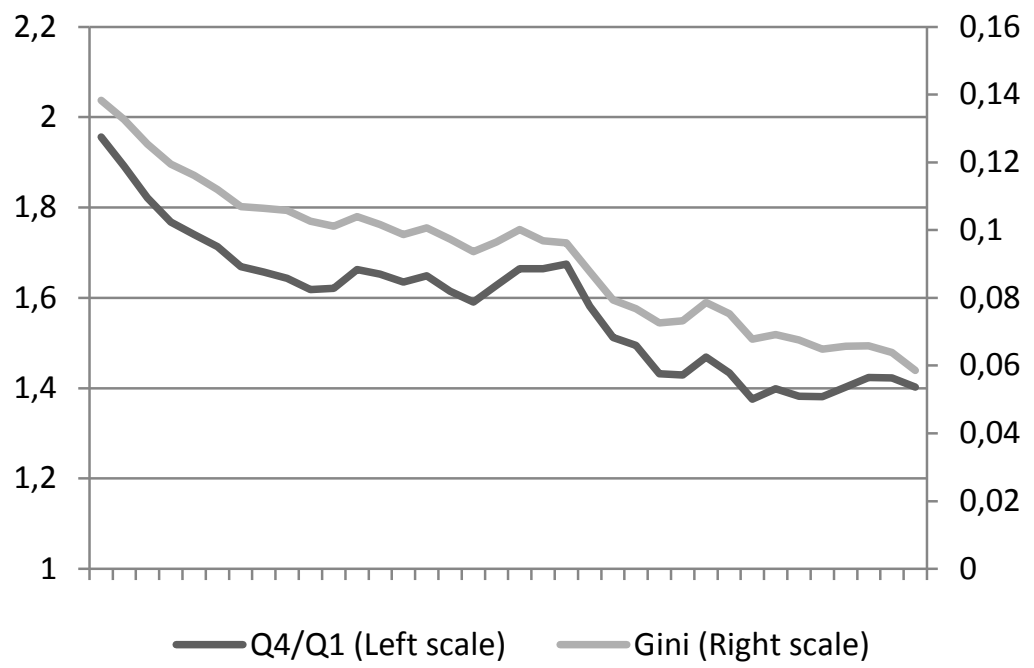

Figure 2. Evolution of the Gini index and the Q4/Q1 ratio for the number of cars per adult in the Paris region (5-year MA).

Source: Continuous Household Surveys (1974-1994) and Car fleet Surveys (1994-2013)

The difference is significant between these two indicators. The level of the Gini index is low, 0.05 around the 2010s. This indicates that the level of car ownership inequality between all the income groups is weak within the whole population. But it does not mean that there is no inequality for specific groups of population (e.g. between the poorest and the wealthiest groups). As shown in figure 1, only Q1 remains below, whereas the other income groups tend to homogenise their behaviour over time. The Q4/Q1 ratio expresses it in showing that high inequalities remain for low income people since the gap of car ownership is still nowadays of $40 \%$ between Q1 and Q4. So, difficulties in access to car still remain for low income people. However, the Paris region includes heterogeneous territories where opposite evolutions of car ownership can be observed. That's why a disaggregation in three zones allows us to qualify the reduction of inequalities presented at global level.

\subsection{Opposite Trends According to the Zone Of Residence}

In Paris (table 1a), where there are very good alternatives to automobile (public transport, walking or cycling for short trips), there has not been a period of car ownership growth during the period under study and we even find a slight reduction of car ownership between 1984 and 2013 (less than 0.4 cars per adult in the 2010s). Thus, the peak of motorisation is an old phenomenon in the central part of the Paris region. Car ownership inequality has decreased 
between 1984 and 2013 (from 2.5 to 1.8 for the Q4/Q1 ratio and from 0.16 to 0.10 for the Gini index). However, the reduction of inequalities is rather due to a fall in car ownership for the richest households than to a change of behaviour for poorer people. Indeed, the number of cars per adult has remained relatively constant for people in Q1 (at 0.25 cars per adult) contrary to a drop for people in Q4 from 0.60 to 0.45 cars per adult. In Q1, the proportion of equipped households ${ }^{3}$ (i.e. households with at least a car) has decreased from $50 \%$ to less than $40 \%$ and in Q4 it has decreased from $72 \%$ to above 55\%. Moreover, the multi-motorisation rate has remained very weak for Q1 around 4-5\% of households with two or more cars and for Q4 it has decreased from 13\% to 5\%. However, inequalities remain substantial between rich and poor people since the gap for the number of cars per adult between Q1 and Q4 is still off $80 \%$ nowadays. Nevertheless, the necessity to own a car for daily trips is reduced thanks to a good public infrastructure which allows low income people to reach the majority of their destinations.

Table 1. Evolution of the number of cars per adult in the four quarters of the income per consumption unit distribution and evolution of inequality indexes according to the residential location

\begin{tabular}{|c|c|c|c|c|c|c|c|}
\hline & Mean & Quarter 1 & Quarter 2 & Quarter 3 & Quarter 4 & Q4/Q1 & Gini \\
\hline 1984-1988 & 0.41 & 0.24 & 0.39 & 0.40 & 0.59 & 2.48 & 0.16 \\
\hline 1989-1993 & 0.37 & 0.25 & 0.32 & 0.38 & 0.52 & 2.12 & 0.15 \\
\hline 1994-1998 & 0.37 & 0.24 & 0.31 & 0.39 & 0.56 & 2.27 & 0.17 \\
\hline 1999-2003 & 0.34 & 0.20 & 0.31 & 0.38 & 0.49 & 2.44 & 0.17 \\
\hline 2004-2008 & 0.36 & 0.25 & 0.30 & 0.38 & 0.51 & 2.00 & 0.14 \\
\hline $2009-2013$ & 0.35 & 0.25 & 0.35 & 0.33 & 0.45 & 1.79 & 0.10 \\
\hline
\end{tabular}

Table 1(b). Evolution of the number of cars per adult and inequality indexes in the inner suburbs

\begin{tabular}{lcccccccc}
\hline & Mean & Quarter 1 & Quarter 2 & Quarter 3 & Quarter 4 & & Q4/Q1 & Gini \\
\cline { 2 - 6 } \cline { 7 - 9 } $\mathbf{1 9 8 4 - 1 9 8 8}$ & 0.52 & 0.39 & 0.46 & 0.58 & 0.65 & & 1.70 & 0.11 \\
$\mathbf{1 9 8 9 - 1 9 9 3}$ & 0.52 & 0.34 & 0.47 & 0.54 & 0.73 & & 2.17 & 0.15 \\
$\mathbf{1 9 9 4 - 1 9 9 8}$ & 0.55 & 0.38 & 0.52 & 0.58 & 0.71 & & 1.88 & 0.12 \\
$\mathbf{1 9 9 9 - 2 0 0 3}$ & 0.55 & 0.40 & 0.51 & 0.56 & 0.73 & & 1.83 & 0.12 \\
$\mathbf{2 0 0 4 - 2 0 0 8}$ & 0.59 & 0.42 & 0.53 & 0.63 & 0.77 & & 1.83 & 0.12 \\
$\mathbf{2 0 0 9 - 2 0 1 3}$ & 0.59 & 0.43 & 0.61 & 0.63 & 0.69 & & 1.63 & 0.09 \\
\hline
\end{tabular}

Table 1(c). Evolution of the number of cars per adult and inequality indexes in the outer suburbs

\begin{tabular}{|c|c|c|c|c|c|c|c|}
\hline & Mean & Quarter 1 & Quarter 2 & Quarter 3 & Quarter 4 & Q4/Q1 & Gini \\
\hline 1984-1988 & 0.58 & 0.47 & 0.50 & 0.63 & 0.72 & 1.52 & 0.09 \\
\hline 1989-1993 & 0.58 & 0.45 & 0.55 & 0.61 & 0.73 & 1.63 & 0.10 \\
\hline 1994-1998 & 0.63 & 0.48 & 0.60 & 0.67 & 0.75 & 1.55 & 0.09 \\
\hline $1999-2003$ & 0.68 & 0.55 & 0.65 & 0.68 & 0.84 & 1.54 & 0.08 \\
\hline 2004-2008 & 0.73 & 0.63 & 0.69 & 0.77 & 0.84 & 1.35 & 0.06 \\
\hline $2009-2013$ & 0.71 & 0.57 & 0.68 & 0.74 & 0.86 & 1.50 & 0.08 \\
\hline
\end{tabular}

Source: Car fleet Surveys (1984-2013)

\footnotetext{
${ }^{3}$ The results about the proportion of equipped and multi-equipped households are not presented in the tables and figures because they serve mainly as an illustration to complete the comments of the results. However, we have used the same method than that presented in the methodology section to express the percentage of households per quarter having a car (or at least 2 cars).
} 
In the inner suburbs (table 1b), car ownership level has slightly increased during the period and tend to reach a saturation threshold ( 0.6 cars per adult) since the mid-2000s. The level of inequalities is intermediate between that of Paris and outer suburbs. In the outer suburbs (table 1c), a maximum of car ownership is reached in the mid-2000s ( 0.7 cars per adult $)$ and a reduction tends to begin in the last period under study. The indicators of inequality remain relatively constant (above 1.50 for the Q4/Q1 ratio and $0.08-0.10$ for the Gini index). It is because the different income groups have followed the same pattern of rise and stabilisation. Considering the motorisation rate per household, the level of inequalities within the whole population is weak in the outer suburbs because the majority of households are equipped in each income quarter. However, 20\% of households are still without a car in Q1 contrary to $7 \%$ of households in Q4. Moreover, inequalities remain important concerning multimotorisation: less than $30 \%$ of household in Q1 have at least two cars contrary to $45 \%$ for Q4 in 2009-2013. Actually, having no car or only one in these zones can be a source of considerable social disadvantages.

Furthermore, the level of both indicators of inequality is decreasing with the distance to the city centre. This expresses the growing importance of access to car in car dependent areas, which tends to reduce the gap and homogenise behaviour between different groups of population. Finally, the saturation of car ownership doesn't appear at the same time for the different place of residence. We notice a kind of diffusion over time of saturation date according to the distance to the city centre (first in Paris and then in the inner suburbs and outer suburbs in the mid-2000s).

\section{Car Use}

5.1. A Stabilisation of Car Use since the Early 1990s and a Decrease at the Turn of the 2000s

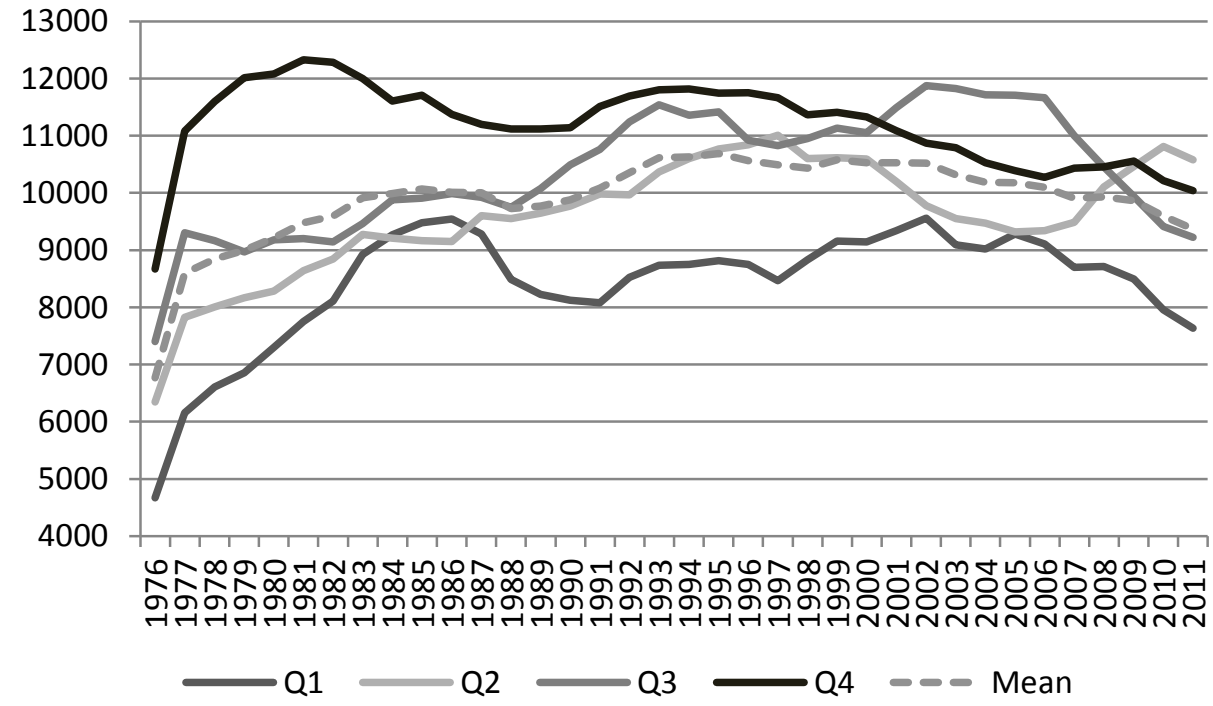

Figure 3. Average annual mileage per household by income quarter per consumption unit in the Paris region (in Km/year, 5-year MA).

Source: Continuous Household Surveys (1974-1994) and Car fleet Surveys (1994-2013) 
In France, the average mileage per household has increased until 2000 and then has decreased. Even if it is not the only factor limiting car use (see the literature review on Peak Car where the different possible causes are discussed), the reduction of car use has appeared in a period of rising fuel price.

However, the limit to the growth of car mileage has happened earlier in the Paris region showing a precursory trend for the decline in car use. After a long period of car use growth, a period of stabilisation during the 1990 s is observed, followed by a reduction since the early 2000s (figure 3). Focusing on income groups, the decline has started in the 1980s in Q4, while for the other quarters the evolution is more fluctuating but there is no global upward trend in Q2 and Q3 since the 1990s and for Q1 since the 1980s. Nowadays we find the same trend as for car ownership where the three highest income groups are rather converging toward 10000 kilometres per year per household, while the lowest quarter remains below with less than $8000 \mathrm{~km} / \mathrm{year}$.

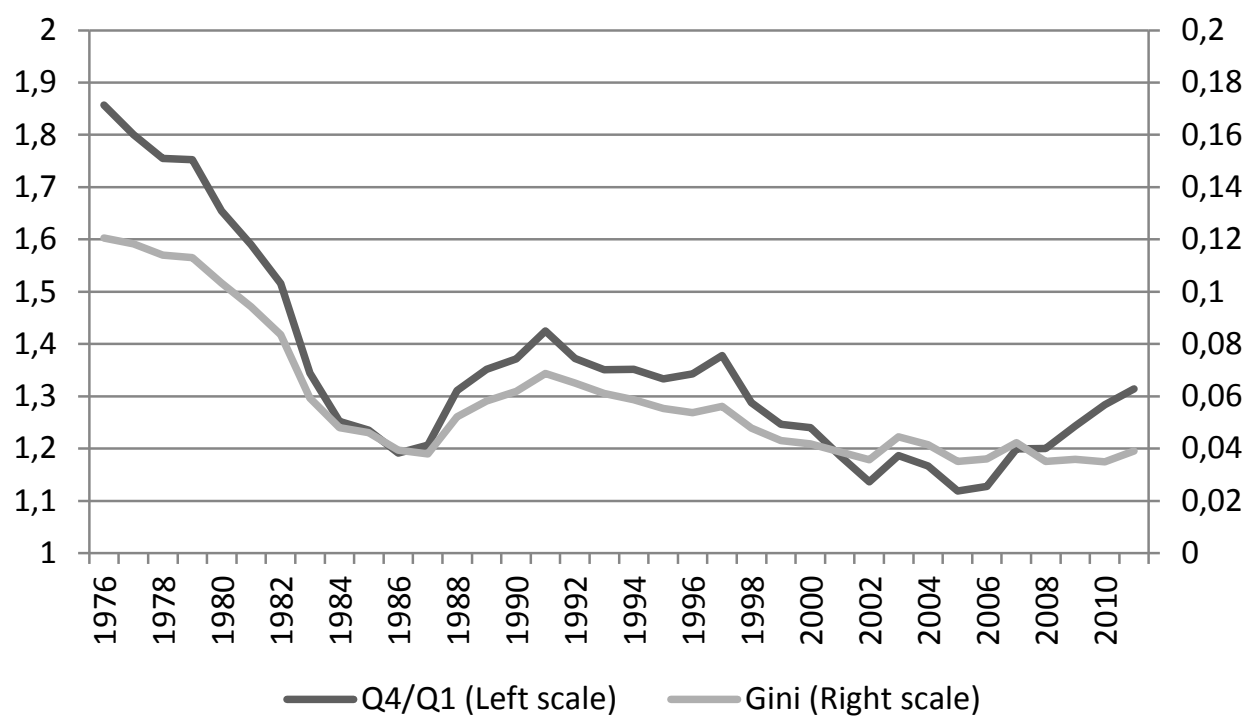

Figure 4. Evolution of the Gini index and the Q4/Q1 ratio for the average annual mileage per household in the Paris region (5-year MA).

Source: Continuous Household Surveys (1974-1994) and Car fleet Surveys (1994-2013)

A strong reduction of inequalities between income groups is observed from 1976 to 2013 (figure 4). The Gini index has decreased from 0.13 to 0.04 and the Q1/Q4 ratio has decreased from 1.9 to 1.3. Even if there has been a strong increase in fuel price between the mid-70s and mid-80s, the reduction of car use inequalities during this period is because of an increasing access to automobile for low income people and a stabilisation of annual mileage for the high income group. After a rise of inequalities in the end of the 1980s due to a reduction of car use mainly for the lowest income group, the Gini index has then decreased during the 1990s. Since the beginning of the 2000s, a stabilisation of the indicator of inequality has been observed showing a global stagnation in the process of social diffusion of car use. Furthermore, the Q4/Q1 ratio has declined from 1990 to 2005 and then increased which can be explained by the relatively strong reduction of car use for people in Q1 in parallel with the rise in fuel price, contrary to a slight decrease for Q4. 
During the period under study, the reduction of inequalities is due to a more homogeneous car use over time for the majority of the population and especially for the three highest income quarters. However, like for car ownership, car use for low income households has remained below and the gap has even increased during the last decade.

\subsection{A progressive saturation of car use in each zone over time}

Table 2. Evolution of the average mileage per household in the four quarters of the income per consumption unit distribution and evolution of inequality indexes according to the residential location

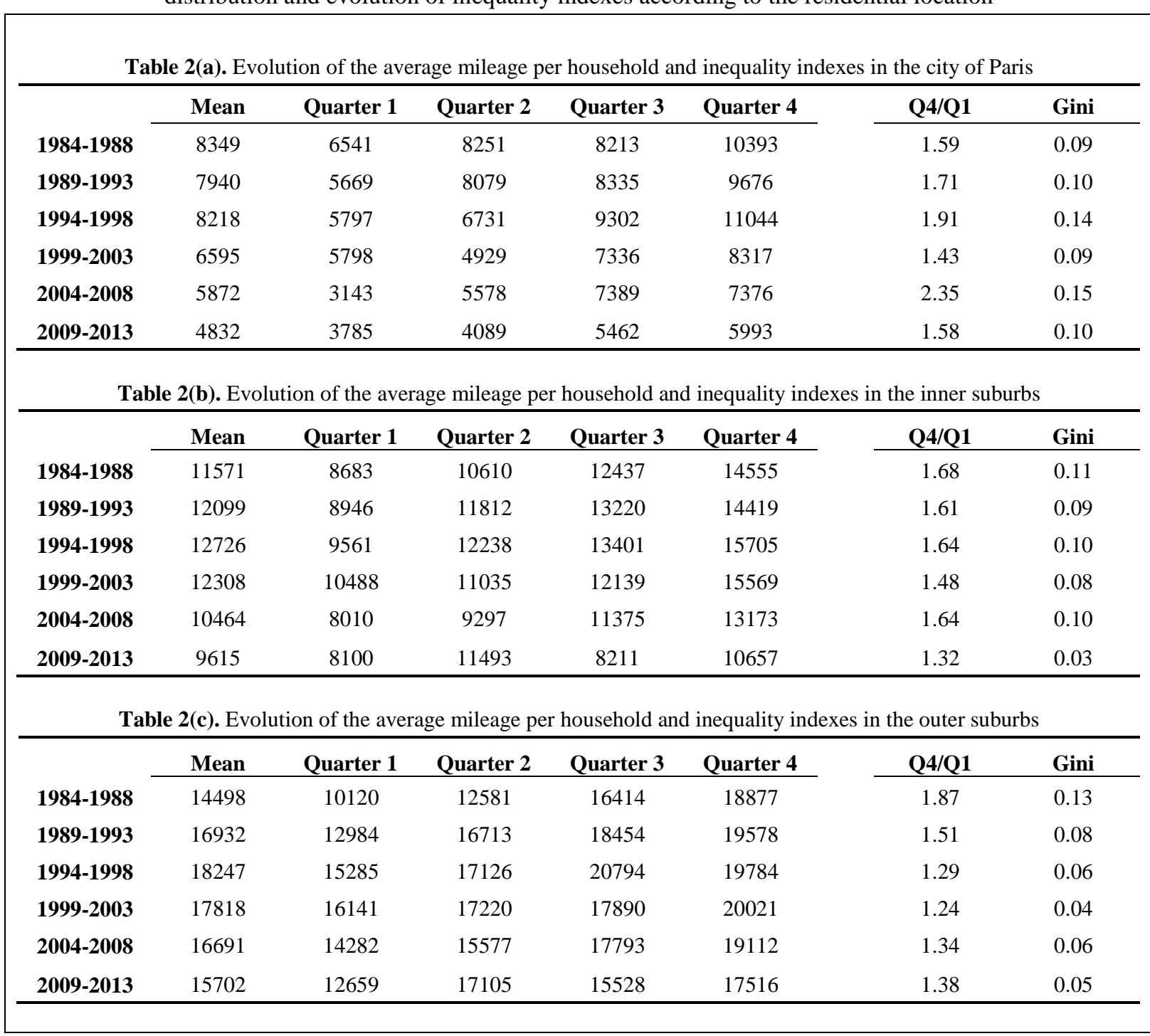

Source: Car fleet Surveys (1984-2013)

In Paris (table 2a), there has been a global saturation of mileage since the beginning of the period under study in the mid-80s, then a decrease of mileage has appeared in the early 2000s in parallel with the rise in fuel price and also with the implementation of policy measures against car use in the city (e.g. bus lanes in Paris have induced a reduction of road space available for cars and a decrease in parking spaces). A strong decrease of annual mileage is shown in each income quarter with a reduction of 35\% for Q1, around $40 \%$ for Q2 and Q3 and 45\% for Q4 between 1999 and 2013. Like for car ownership, the level of the indicators of 
inequality is higher in Paris than in the suburbs because there are alternatives to automobile. Low income households can moderate their mileage, which increases the gap between income groups.

In the inner suburbs (table 2b), a maximum of car use is observed during the period 19941998 but the rise was moderate before. In the outer suburbs (table 2c), there has been a strong increase of car use between the mid-1980s and the end of the 1990s in each income quarter and in particular in Q1, which entails a convergent behaviour of households and a decrease of the inequality indicators which are lower than in more central areas. Afterward a decrease of mileage has emerged. During the period 2004-2008, which corresponds to a strong rise in fuel price, the reaction of people has diverged according to their income level and their zone of residence. In Paris, there is a strong increase of the inequality indicators because households in Q1 have reduced significantly their mileage (-45\%). On the contrary, in the outer suburbs, all income groups have reduced their mileage in similar proportion so the inequality indicators have remained almost unchanged during the same period. Furthermore, in densely populated areas, where there are alternatives to car use, poor people tend to have a higher elasticity to fuel price contrary to people in less urbanised areas where their elasticity is lower because of car dependency. If we observe a streamlining of car use with a reduction of mileage in each area, this possibility is more limited in car dependent areas.

Concerning the 'Peak Car', there is a progressive saturation of car use in each zone over time. First, in the city of Paris, there is no upward trend of mileage since the mid-80s; then a threshold appeared in the inner and outer suburbs in the end of the 1990s.

\section{Discussion}

\subsection{Study limitations}

This paper proposes an insight into the dynamics of car ownership and use inequalities between groups of population using a longitudinal perspective from the 1970s. It should be noted that these indicators are only a proxy of accessibility. The accessibility and participation of people are seen implicitly through the availability of automobile and the mileage travelled. Thus, we do not take into account the access to key destinations (employment, education or health care, etc.). The analysis is de facto limited to the scope of the surveys which are not origin-destination surveys, but annual surveys on car ownership and mileage. Moreover, the indicators measure inequalities of access and mileage in relation with income but not directly social disadvantages. If transport and social disadvantages are often linked, the relation is not systematic since people can be socially excluded without transport disadvantages and vice versa (Currie and Delbosc, 2010; Lucas, 2012). Finally, different interpretations of the indicators are possible and depend on the study undertaken, especially on spatial aspects. We will discuss it below.

\subsection{Evolution of car travel behaviour and the "Peak Car" hypothesis}

In a previous paper, Collet et al. (2012) have modelled the diffusion of car ownership and use in France and in the whole Paris region. Sigmoid functions have been adjusted on the concave curves representing the trends for the average number of cars per adult and the annual mileage 
per household. This specification allows the estimation of saturation thresholds for each quarter of households according to their standard of living (table 3). These saturation thresholds, estimated with tight confidence intervals, are close to the levels reached today showing that the process of diffusion of automobile in the Paris region is close to have achieved its limits in the current state of fuel price, real income and transport infrastructures.

Table 3. Saturation thresholds estimated in the Paris metropolitan area

\begin{tabular}{ccccc}
\hline & $\mathbf{Q 1}$ & $\mathbf{Q 2}$ & $\mathbf{Q 3}$ & $\mathbf{Q 4}$ \\
\cline { 2 - 5 } Number of cars per adult & 0,42 & 0,54 & 0,63 & 0,62 \\
Annual mileage per household & 8643 & 10061 & 10742 & 10717 \\
\hline Source: Collet et al. (2012) - Continuous Household Surveys (1974-1994) and Car fleet Surveys (1994-2010)
\end{tabular}

However, as shown in this paper, the evolution of car ownership and use over time is heterogeneous and the maximum has not appeared at the same time in the different place of residence. This leads to question the nature of the saturation reached.

For car use, the phenomenon of saturation has appeared in the 80s for the inhabitants of the City of Paris. Car use has followed a downward trend for a long time, so the reduction seems to be a long term phenomenon. While in the inner and outer suburbs, the saturation has appeared in the beginning of the 2000s and has been influenced by fuel price in particular. For car ownership, we find the same process as for car use where the stabilisation is more recent in territories distant from the centre. Indeed, the stabilisation of car ownership is a long term phenomenon in the city centre (since the 1980s) while the maximum is more recent in the suburbs (in the mid-2000s).

Thus, concluding about the permanence of the saturation in the suburbs is a complex issue within the framework of this paper. The reduction of car ownership and use may only be a temporary phenomenon and it could rise again if the economic situation improves in the future.

\subsection{Interpretation of inequalities}

Automobile holds a dominant position in today's society. The evolution of land use structure and the diversification of activity programs have been permitted by the democratisation of automobile. Trips are today more oriented toward peripheral movements than radial movements, limiting the performance of public transport. Thus, owning a car is not a privilege, but above all a necessity for many people especially in low density areas. There has been a growing equality in the distribution of car ownership and use through a converging behaviour in the Paris region. If the differences are not discriminating for the majority of the population, inequalities still remain mainly for low income people. Behaviour of people in Q2, Q3 and Q4 has come progressively closer while the behaviour of people in Q1 has remained below with fewer cars per adult and a lower annual mileage per household.

However, the indicators must not be interpreted in the same way depending on the zone of residence. In Paris, inequalities are more important but 'less constraint' because many destinations can be reached by foot, bicycle or public transport. As a consequence, having a 
car is often unnecessary for daily trips. On the contrary, in the outer suburbs where the position of automobile is dominant, inequalities are 'more constraint' and should be interpreted as a problem of inequity because it can reflect inequalities in accessibility and participation in social life. One of the major inequalities is the relatively important percentage of low income households without a car or having only one car.

In a zone where public transport supply is often partial with a weak territorial grid (in the outer suburbs the public transport network is radial, oriented toward Paris and not to other suburbs) $20 \%$ of low income households still don't have a car and more than $70 \%$ have only one car which implies a problem of car availability for certain members in the household for their own trips. Having no car or only one may reinforce the insulation of certain members of the household in their nearby living territory and may cause a problem of social exclusion. Wenglenski (2006) has shown that for a given access time and for a specific socioprofessional group, the number of jobs reachable by public transport in the outer suburbs is considerably lower than for equivalent people living in Paris or in the inner suburbs and the gap is even larger for low income people living in the outer suburbs.

Then, the reduction of the gaps in motorisation and use due to an increasing necessity to own a car leads to a more important part of automobile (purchase and user cost) in the budget of certain households. Indeed, increasing fuel price and degraded economic conditions may have made some households more vulnerable, especially low income households living in low density areas (Berri, 2007; Nicolas, Vanco \& Verry, 2012), whose travel budgets have been increasing in parallel with a greater car dependency. Automobile represents a fifth of their budget and even a quarter for low income households in the outer suburbs of the Paris region; and taking into account the cost of housing, it can reach three-quarters of their budget contrary to less than $50 \%$ in the inner suburbs (Coulombel \& Deschamps, 2008). An increasing vulnerability tightens the need for specific policies maintaining mobility for low income households living without car alternatives (Berri, 2007).

\subsection{Implications for policy}

Different visions of equity are put forward by these two indicators. The Gini index expresses the gap it remains with regards to perfect equality, thus refers to egalitarism (horizontal equity). Indeed, the aim of egalitarism is that everyone shares the same conditions. The $\mathrm{Q} 4 / \mathrm{Q} 1$ ratio can be interpreted in terms of vertical equity since it expresses the gap between the two extreme groups of the standards of living distribution, thus show the possible effort to improve the situation for low income group and to narrow the gap between different groups of population.

As explained above, the level of the Gini index is low, pointing out that the difference in car ownership and use distribution between income groups has reduced over time and tend to level out. But the level of the Q4/Q1 ratio expresses that low income people remain in need. As the problem of car accessibility or use with regards to income distribution concerns mainly a small part of the population, vertical equity with specific decisions seems to be more appropriate for appraising social justice. Thus, the question is how to reduce the gap of access to car and mobility between the lowest income group and the rest of the population. Here, the 
objective is not to provide exhaustive recommendations, but rather to point out some potential levers and their implications in terms of equity.

Policies can help access to driving licence (one euro per day licence for instance), support an affordable access to car and mobility (purchase loans programs and pay-as-you-drive insurance). These actions can benefit to all but especially have a positive influence on access to car and use for low income groups which can reduce the level of inequality shown by Q4/Q1 indicator. However, these measures can be regressive because they tend to put pressure on these people by increasing the part of transport in their budget and could be a burden for certain vulnerable groups. Thus, policies that encourage multi-modal transport system (public transport, carsharing, walking, cycling...) and housing in accessible locations can benefit all residents and in particular increase social equity by improving the mobility of disadvantaged people (Rodier, et al. 2010).

So, poor people can take advantage of specific policies that help to own a car, but they can benefit more from policies favouring diverse travel options and housing in accessible locations. However, these options go beyond the spectrum of our indicators. Indeed, we only have only focussed our analysis on automobile and we do not take into account the other modes of transport in the indicators. Thus, other indicators are needed to supplement the analysis of inequalities.

\section{References}

Berri, A. (2007). Residential location and household expenditures for transport and housing the example of the Greater Paris region. Paper presented at the 11th World conference on Transport Research, 24-28 June 2007, Berkeley, CA.

Berri, A., Vincent Lyk-Jensen, S., Mulalic, I., \& Zachariadis, T. (2014). Household transport consumption inequalities and redistributive effects of taxes: A repeated cross-sectional evaluation for France, Denmark and Cyprus. Transport Policy, 36, 206-216.

Brown, M., (1994). Using gini-style indices to evaluate the spatial patterns of health practitioners: Theoretical considerations and an application based on Alberta data. Social science and medicine, 38(9), 1243-1256.

Buehler, R., \& Pucher, J. (2012), Demand for public transport in Germany and the USA : An Analysis of Rider Characteristics, Transport Reviews, 32(5), 541-567.

CCTN (2012). Les transports en 2011 : 49ème rapport à la Commission des comptes des transports de la Nation. CGDD, Paris.

Cervero, R. (2004). Job isolation in the US: Narrowing the gap through job access and reverse commute programmes. In Lucas, K. (Ed.), Running on Empty: Transport social exclusion and environmental justice. Policy Press, Bristol, United Kingdom.

Choquet, O. (1983). L'automobile, un bien banalisé. Economie et Statistique 154 (1), 47-55.

Church, A., Frost, M., \& Sullivan, K. (2000). Transport and social exclusion in London. Transport Policy, 7, 195-205.

Collet, R. (2012). Household car use in France: a demographic and economic analysis. Economics Bulletin, 32(1), 475-485.

Collet, M., Madre, J-L., \& Hivert, L. (2012). Diffusion de l'automobile en France: Vers quels plafonds pour la motorisation et l'usage ? Economie et Statistiques, 457-458, 123-139.

Coulombel, N., \& Deschamps, M. (2008). Les ménages arbitrent-ils entre budget logement et budget transport ? Une analyse pour la région parisienne. In de Coninck F. \& Deroubaix J.-F. (eds) Ville 
éphémère / ville durable. Multiplication des formes et des temps urbains, maîtrise des nuisances : nouveaux usages, nouveaux pouvoirs (pp.205-216), Paris, L'Eil d'Or.

Currie, G., \& Delbosc, A. (2010). Modelling the social and psychological impacts of transport disadvantage. Transportation, 18, 31-41.

Delbosc, A., \& Currie, G. (2011). Using Lorenz curves to assess public transport equity. Journal of Transport Geography, 19, 1252-1259

Delbosc, A. \& Currie, G. (2013). Causes of youth licensing decline: a synthesis of evidence. Transport Reviews, 33(3), 271-290.

De Solère (2012). La décennie tramway. In: «La mobilité urbaine des années 2000 », CERTU.

Dupuy, G. (1999). La dépendance automobile : symptômes, analyses, diagnostic, traitements. Anthropos, Paris.

Gargett, D. (2012). Traffic growth: Modelling a global phenomenon (Report No. 128). Canberra ACT: BITRE (Bureau of Infrastructure, Transport and Regional Economics).

Goodwin, P. (2012). Peak travel, peak car and the future of mobility : Evidence, unresolved issues, policy implications, and a research agenda (Discussion Paper No. 13). Paris: OECD/ITF Roundtable on Long-run Trends in Travel Demand.

Goodwin, P. \& Van Dender, K. (2013). The prospects for future levels of car access and use? Transport Reviews, 33(3), 243-254.

Headicar, P. (2013). The changing spatial distribution of the population in England : Its Nature and Significance for 'Peak car'. Transport Reviews, Special Issue $n^{\circ} 1$ on 'Peak car'.

Hivert, L., Ottmann, P., Krakutovski, Z., Legros, D., Chlond, B., Madre J.-L. \& Zumkeller D. (2008). Multimodalité et tendances démographiques - CADMIUM : Comparative analysis of demographic modifications and impact on the longitudinal use of modes. Deufrako-Predit3 pour ADEME, INRETS \& IfV Karlsruhe Universität, 202p.

Hivert, L., \& Madre, J-L. (2012). L'adaptation des ménages aux hausses du prix des carburants, in: La mobilité urbaine en France - Enseignements des années 2000-2010. CERTU.

Hubert, J.-P., Madre, J.L., Meissonnier, J., \& Roux, S. (2013). La pause méridienne : un facteur clé de l'évolution de la mobilité en France depuis 35 ans. Economie et Statistique, 457-458, 35-55.

International Transport Forum (ITF) (2011). Transport outlook - Meeting the needs of 9 billion people. Paris: ITF.

Karlström, A., \& Franklin, J.P. (2009). Behavioral adjustments and equity effects of congestion pricing: Analysis of morning commutes during the Stockholm Trial. Transportation Research Part A, 43, 283-296

Kenyon, K., Lyons, G, \& Rafferty, J. (2002). Transport and social exclusion: Investigating the possibility of promoting inclusion through virtual mobility. Journal of Transport Geography, 10(3), 207-219.

Kuhnimhof, T., Armoogum, J., Buehler, R., Dargay, J., Martin Denstadli, J. \& Yamamoto, T. (2012). Men shape a downward trend in car use among young adults - evidence from six industrialized countries. Transport Reviews, 32(6), 761-779.

Kwok, R.C.W., \& Yeh, A.G.O. (2004). The use of modal accessibility gap as an indicator for sustainable transport development. Environment and planning A, 36(5), 921-936.

Litman, T. (2013). Changing North American vehicle-travel price sensitivities: Implications for transport and energy policy. Transport Policy, 28, 2-10.

Litman, T. (2014). Evaluating transportation equity: guidance for incorporating distributional impacts in transportation planning. Victoria Transport Policy Institute.

Lucas, K. (2006). Providing transport for social inclusion within a framework for environmental justice in the UK. Transportation Research Part A: Policy and Practice, 40, 801-809.

Lucas, K. (2012). Transport and social exclusion: where are we now? Transport Policy, 20, 105-113.

Lucas, K., van Wee, B., \& Maat, K. (2015). A method to evaluate equitable accessibility: combining ethical theories and accessibility-based approaches. Transportation (in press), 1-18.

Madre, J.-L. (1989). Les ménages et l'automobile: originalité et contrastes. Données Sociales Ile-deFrance (INSEE).

Martens, K. (2011). Substance precedes methodology: on cost-benefit analysis and equity. Transportation, 38(6), 959-974. 
Martens, K., Golub, A., \& Robinson, G. (2012). A justice-theoretic approach to the distribution of transportation benefits: Implications for transportation planning practice in the United States. Transportation Research Part A, 46, 684-695.

Metz, D. (2010). Saturation of demand for daily travel. Transport Reviews, 30(5), 659-674.

Mignot, D., \& Rosales-Montano, S. (2006). Vers un droit à la mobilité pour tous. Inégalités, territoires et vie quotidienne. La Documentation Française PUCA, Paris, 97p.

Millard-Ball, A., \& Schipper, L. (2011). Are we reaching peak travel? Trends in passengers transport in eight industrialized countries. Transport Reviews, 31(3), 357-378.

Murakami, E., \& Young, J. (1997, October). Daily travel by persons with low income. Paper for NPTS Symposium, Betheda, MD.

Nicolas, J-P., Vanco, F., \& Verry, D. (2012). Mobilité quotidienne et vulnérabilité des ménages. Revue d'économie régionale et urbaine, 2012 (1), 19-44.

Ong, P., \& Blumenberg, E.A. (1998). Job access, commute and travel burden among welfare recipients. Urban Studies, 35, 77-93.

Orfeuil, J.P. (2004). La mobilité, nouvelle question sociale ?. SociologieS.

Paulo C., 2007, Une mesure des inégalités de mobilité et d'accès au volant. Retrieved from http://www.espacestemps.net/articles/une-mesure-des-inegalites-de-mobilite-et-acces-au-volant/

Pucher, J., \& Renne, J. (2003). Socio-economics of urban travel: evidence from the $2001 \mathrm{nhtS}$, Transportation Quarterly, 57 (3), 49-77.

Puu, T., 2005. On the genesis of hexagonal shapes. Networks \& Spatial Economics 5, 5-20.

Rietveld, P., Rouwendaal, J., \& van der Vlist, A. (2007). Equity issues in the evaluation of transport policies and transport infrastructure projects. In: van Geenhuizen, M., Reggiani, A., \& Rietveld, P. (eds.) Policy Analysis of Transport Networks (pp. 19-36). Aldershot, Ashgate.

Rodier, C., Abraham, J., Dix, B., \& Hunt, J. (2010). Equity analysis of land use and transport plans using an integrated spatial model, Report 09-08, Mineta Transportation Institute

Sivak, M, \& Schoettle, B. (2012). Recent changes in the age composition of drivers in 15 countries. Traffic Injury Prevention, 13, 126-132.

Social Exclusion Unit (SEU) (2003). Making the connections: Final report on transport and social exclusion. London: Office of the Deputy Prime Minister.

SOeS (2012). La circulation routière augmente à un rythme ralenti depuis 2003. Commissariat Général au Développement Durable, 118.

STIF (2012). Enquête Globale Transport, La mobilité en Ile-de-France, no.1 Sept 2012

Verbeek, M., \& Nijman, T. (1992). Can cohort data be treated as genuine panel data? Empirical Economics, 17, 9-23.

Wenglenski S. (2004). Une mesure des disparités sociales d'accessibilité au marché de l'emploi en Îlede-France. Revue d'Economie Régionale et Urbaine, 4, 539-550.

Wenglenski, S. (2006). Regards sur la mobilité au travail des classes populaires. Une exploration du cas parisien. Cahiers scientifiques du transport, 49, 103-127. 